\title{
Spontaneous bleeding of hepatocellular carcinoma during pregnancy
}

\author{
Marco Scioscia $^{1} \cdot$ Marco Noventa $^{1,2}$ D $\cdot$ Anna Vitulo $^{1} \cdot$ Francesca Basile $^{1}$
}

Published online: 28 December 2020

(c) The Author(s) 2020

Keywords Pregnancy $\cdot$ Liver $\cdot$ Carcinoma $\cdot$ Bleeding

Place Fig. 1.

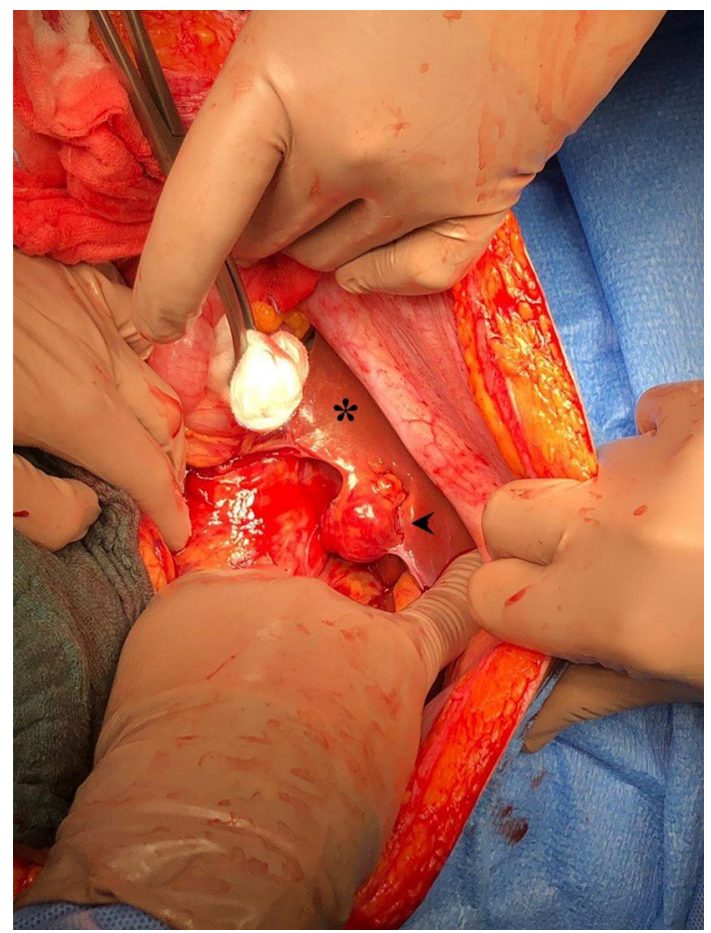

Fig. 1 A 31-year-old primigravida at 40 weeks of gestation sought care for onset of severe abdominal pain. Ultrasound revealed a moderateto-marked amount of hypoechoic free fluid in abdomen. Emergency caesarean section was performed with no evidence of uterine rupture. Active hemorrhage came from a $2.5 \mathrm{~cm}$-sized neoplasm in the right lobe of liver. Nodulectomy was performed and histology confirmed hepatocellular carcinoma. *Normal liver. Arrow—Bleeding neoplasm

Marco Noventa

marconoventa.md@gmail.com

1 Department of Obstetrics and Gynecology, Policlinico Hospital, Abano Terme, Padua, Italy

2 Department of Women's and Children's Health, Clinic of Gynecology and Obstetrics, University of Padua, Via Giustiniani 3, 3100 Padua, Italy
Funding Open access funding provided by Università degli Studi di Padova within the CRUI-CARE Agreement.

\section{Compliance with ethical standards}

Conflict of interest The authors declare that they have no conflict of interest.

Consent to participate The authors obtained an informed consent from the patient for imaging reporting.

Open Access This article is licensed under a Creative Commons Attribution 4.0 International License, which permits use, sharing, adaptation, distribution and reproduction in any medium or format, as long as you give appropriate credit to the original author(s) and the source, provide a link to the Creative Commons licence, and indicate if changes were made. The images or other third party material in this article are included in the article's Creative Commons licence, unless indicated otherwise in a credit line to the material. If material is not included in the article's Creative Commons licence and your intended use is not permitted by statutory regulation or exceeds the permitted use, you will need to obtain permission directly from the copyright holder. To view a copy of this licence, visit http://creativecommons.org/licenses/by/4.0/.

Publisher's Note Springer Nature remains neutral with regard to jurisdictional claims in published maps and institutional affiliations. 